\title{
Erratum to: Moving Transgender Care Forward within Public Health Organizations: Inclusion of Facial Feminizing Surgery in the Swedish National Treatment Recommendations
}

\author{
T. Kalle Lundgren ${ }^{1,2} \cdot$ Josef Isung $^{1,4} \cdot$ Johan Rinder $^{5} \cdot$ Cecilia Dhejne $^{4,7}$ • \\ Stefan Arver ${ }^{3,4} \cdot$ Lars-Erik Holm $^{6} \cdot$ Filip Farnebo ${ }^{1,2}$
}

Published online: 22 September 2016

(C) Springer Science+Business Media New York 2016

\section{Erratum to: Arch Sex Behav \\ DOI 10.1007/s10508-016-0830-3}

Please note that the name of one of the authors of this Letter to the Editor was missing from the author line of the letter as originally published.
The name of Cecilia Dhejne was missing from the author line (between the names of Johan Rinder and Stefan Arver).

The online version of the original article can be found under doi:10.1007/ s10508-016-0830-3.

T. Kalle Lundgren

Kalle.Lundgren@ki.se

1 Department of Molecular Medicine and Surgery, Karolinska Institutet, Stockholm, Sweden

2 Stockholm Craniofacial Center, Karolinska University Hospital, 17176 Stockholm, Sweden

3 Department of Medicine/Huddinge, Karolinska Institutet, Stockholm, Sweden

4 ANOVA, Karolinska University Hospital, Stockholm, Sweden

5 Unit of Nationalised Specialised Medical Care, Karolinska University Hospital, Stockholm, Sweden

6 National Board of Health and Welfare, Stockholm, Sweden

7 Department of Clinical Neuroscience, Center for Psychiatric Research, Karolinska Institutet, Stockholm, Sweden 